Check for updates

Cite this: RSC Adv., 2017, 7, 55224

Received 1st November 2017 Accepted 29th November 2017

DOI: 10.1039/c7ra12001j

rsc.li/rsc-advances

\section{Electrospun polyacrylonitrile/ $\beta$-cyclodextrin based porous carbon nanofiber self-supporting electrode for capacitive deionization}

\author{
Hexuan Zhang, Zhengzheng Xie, Yanbo Wang, Xiaohong Shang, Pengfei Nie \\ and Jianyun Liu (iD)*
}

With $\beta$-cyclodextrin ( $\beta-C D)$ as an additive, porous carbon nanofibers $\left(P C N F_{\beta-C D}\right)$ with good graphitization have been fabricated by electrospinning polyacrylonitrile/ $\beta$-cyclodextrin (PAN/ $\beta-C D$ ) pristine fibers followed by preoxidation and carbonization. The nanopores were formed by the dehydration and decomposition of $\beta-C D$ at high temperature. The specific surface area and pore density can be conveniently tuned by adding different amounts of $\beta-C D$ in the precursor solution. The resultant porous carbon fibers were characterized by scanning electron microscopy, $\mathrm{N}_{2}$ adsorption/desorption analysis and fourier transform infrared spectroscopy. Raman analysis indicates that the graphitic network of the porous carbon is improved with the addition of $\beta-C D$. With the porous carbon fiber web as a selfstanding electrode, the electrochemical properties of the electrodes were investigated by cyclic voltammetry and electrochemical impedance spectroscopy. $\mathrm{PCNF}_{\beta-\mathrm{CD}}$ were employed as active electrodes for capacitive deionization (CDI). The optimal desalination amount of $11.65 \mathrm{mg} \mathrm{g}^{-1}$ was achieved on the $P C N F_{\beta-C D}$ fabricated with the $P A N / \beta-C D$ ratio of $1: 0.8$, which is significantly higher than that of pure PAN-based carbon nanofibers. Multiple charge-discharge cycling of the CDI cell was tested and the regeneration of the electrode was demonstrated.

\section{Introduction}

Capacitive deionization (CDI) is a desalination method for removing dissolved salts from saline water by their adsorption onto electrode surfaces with the formation of electric doublelayers upon applying an external voltage between two oppositely charged carbon electrodes. Of late, attention has become focused on the development of CDI technology because of its advantages, such as low direct voltages, low operation pressure, low-cost, no-secondary pollution and environmentallyfriendliness in water desalination. ${ }^{\mathbf{1 , 2}}$ To achieve the desired desalination efficacy, the electrode materials must have the following characteristics such as high specific surface area, good electrical conductivity, robust chemical inertness, and large capacitance etc. ${ }^{3}$ Various porous carbon materials including activated carbon, ${ }^{4-6}$ carbon aerogels, ${ }^{7-9}$ ordered mesoporous carbon, ${ }^{\mathbf{1 0 - 1 2}}$ carbon nanofibers, ${ }^{\mathbf{1 3}, 14}$ carbon nanotubes $^{15-17}$ and graphene ${ }^{18,19}$ have been employed as the CDI electrode, due to high conductivity, high specific surface area and excellent chemical stability. Among of them, carbon nanofiber is an excellent candidate for ionic adsorption. It can

College of Environment Science and Engineering, State Environment Protection Engineering Center For Pollution Treatment and Control in Textile Industry, Donghua University, 201620 Shanghai, People's Republic of China. E-mail: jianyun. liu@dhu.edu.cn be used as a self-supporting electrode with good electrical conductivity since no insulting adhesive (such as PTFE, PVDF) is added in the electrode. Recently, electrospinning technique, as a simple and low-cost method, has become a popular tool for producing carbon nanofibers. ${ }^{20}$ Polyacrylonitrile (PAN) is often used as a carbon source due to its good mechanical property and high carbon yield. ${ }^{21}$ However the resulting carbon fibers have low surface area owing to the lack of pores. ${ }^{13}$ Polymethyl methacrylate (PMMA), polystyrene (PS), polyvinyl alcohol (PVA) or dimethyl sulfone $\left(\mathrm{DMSO}_{2}\right)$ have been mixed with PAN as the sacrificial components to obtain the porous carbon fibers. ${ }^{22-25}$ These chemicals can decompose and pores are formed upon carbonization at high temperature. However, the formation of nonuniform macro pores in the fibers often leads to the poor mechanical property of carbon fiber and low carbon yield. Some inorganic oxides such as $\mathrm{ZnO}, \mathrm{Al}_{2} \mathrm{O}_{3}$ or $\mathrm{SiO}_{2}$, could also been used as pore-forming reagents to mix with the carbon precursor PAN. ${ }^{26,27}$ Following the carbonization at high temperature, these inorganic oxides can be removed by chemical etching and the pores are then formed. This procedure is undoubtedly complex and the aggressive process such as chemical etching is inevitable. ${ }^{28}$

Cyclodextrins (CDs) are one class of the cyclic oligosaccharides compounds being composed of six or more $\alpha$-(1-4)-linked D-glucopyranose units. ${ }^{29}$ There are $\alpha$-CD, $\beta$-CDs and $\gamma$-CD corresponding to the D-glucopyranose of 6,7 and 8 units. It 
presents a typical inner hydrophobic and outer hydrophilic structure. CDs are known to be a desirable carbon precursor which can dehydrate and decompose into a fine graphitic $\mathrm{sp}^{2}$ network during carbonization because of strong bonding between the CDs which would lead to an ordered structure. ${ }^{\mathbf{3 0 , 3 1}}$ The cavity of CDs may contribute to the porosity of the resultant carbon. CDs can be dissolved compatibly in a PAN solution. The PAN/CD fibers have been prepared for adsorption application. ${ }^{32}$ However, to the best of our knowledge, the porous carbon fiber with CDs as both pore-forming reagent and carbon source has not yet been explored.

In this paper, the porous carbon nanofibers were fabricated by electrospinning the mixture of PAN and $\beta$-CD followed by heat treatment. In light of the dehydration and decomposition property of $\beta$-CD at high temperature, the meso/micropores can be formed in the nanofibers in one carbonization step, without additional activation. In addition, the pore density is tunable, depending on the PAN/ $\beta-C D$ ratio. The obtained porous carbon nanofiber $\left(\mathrm{PCNF}_{\beta-\mathrm{CD}}\right)$ web is used as a self-supporting electrode in capacitor. The electrochemical behavior and CDI desalination properties of the $\mathrm{PCNF}_{\beta-\mathrm{CD}}$ were investigated. This work presents a new way to the preparation of a porous carbon material with cyclodextrin as both a secondary carbon source and a pore-forming reagent.

\section{Experimentals}

\subsection{Preparation of porous carbon nanofibers (PCNFs)}

$1 \mathrm{~g}$ of polyacrylonitrile (PAN, MW = 150 000, Aldrich, 99.8\%) was dissolved in a $10 \mathrm{~mL}$ of $\mathrm{N}, \mathrm{N}$-dimethyl formamide solvent (DMF, Sinopharm Chemical Reagents, 99.5\%) to get a homogeneous PAN solution by stirring at $60{ }^{\circ} \mathrm{C}$ for $12 \mathrm{~h}$. Different amount of $\beta$-cyclodextrin ( $\beta$-CD, Sinopharm Chemical Reagent Co., Ltd) was then added into the PAN solution and stirred again to form the precursor solutions with different mass ratios of PAN/ $\beta$-CD (PAN : $\beta$-CD $=1: 0.4,1: 0.6,1: 0.8,1: 1)$. The PAN solution without $\beta-\mathrm{CD}$ (PAN : $\beta-\mathrm{CD}=1: 0)$ was used to prepare the control sample.

The electrospinning process is similar to the literature method, ${ }^{25}$ but a rotating drum wrapped with Al foil was used as a collector. The rotation rate of the drum was $60 \mathrm{rpm}$. The optimal operation parameters including the voltage of $15 \mathrm{kV}$, flow rate of $1 \mathrm{~mL} \mathrm{~h}^{-1}$ and tip-collector distance of $15 \mathrm{~cm}$ were used to get the uniform and continuous nanofibers (NFs). The pristine NFs $(1: 0),(1: 0.4),(1: 0.6),(1: 0.8)$ and $(1: 1)$ were obtained by electrospinning the PAN/ $\beta$-CD solution $(1: 0$, $1: 0.4,1: 0.6,1: 0.8$ and $1: 1)$, respectively.

The pristine nanofibers were heated till $260^{\circ} \mathrm{C}$ at $2{ }^{\circ} \mathrm{C} \mathrm{min}{ }^{-1}$ in a furnace in an air atmosphere, and held at $260{ }^{\circ} \mathrm{C}$ for $90 \mathrm{~min}$ to get the pre-oxidized NFs. After cooling down, the samples were then transferred into a tube furnace for carbonization in $\mathrm{N}_{2}$ atmosphere. The fibers were heated under temperatureprogrammed heating conditions where the reaction temperature was raised to $800{ }^{\circ} \mathrm{C}$ at a rate of $5{ }^{\circ} \mathrm{C} \mathrm{min}{ }^{-1}$. After holding at $800{ }^{\circ} \mathrm{C}$ for $2 \mathrm{~h}$, the furnace cooled down to room temperature to get the porous carbon nanofibers $\left(\mathrm{PCNF}_{\beta-\mathrm{CD}}\right)$. The PCNFs derived from different pristine NFs $(1: 0,1: 0.4,1: 0.6,1: 0.8$ and $1: 1)$ were represented with $\operatorname{PCNF}_{\beta-\mathrm{CD}}(1: 0,1: 0.4,1: 0.6$, $1: 0.8$ and $1: 1$ ), respectively.

\subsection{Characterization}

The morphology of electrospun nanofibers was examined by scanning electron microscopy (SEM, S-4800, Hitachi, Japan). Fourier transform infrared spectroscopy (FTIR) experiment was performed in a range of $400-4000 \mathrm{~cm}^{-1}$ using a Nicolet iN10 MX spectrometer (ThermoFisher, USA). Raman spectra were obtained with the inVia-Reflex from Britain. Thermal gravimetric (TG) analyzer (TGA 4000, PerkinElmer) was used for the study of the decomposition process of the samples. Nitrogen sorption analysis was carried out with porosimetry instrument (ASAP2020, Micromeritics). The specific surface area was obtained using Brunauer Emmette Teller (BET) calculation. The pore size distribution plots were recorded from the desorption part of the isotherms in light of the Barrette Joynere Halenda (BJH) model. ${ }^{33}$

The electrochemical capacitor property of the electrode was investigated in a two-electrode cell using cyclic voltammetry (CV) on the CHI760D workstation (Shanghai Chenhua instrument Co., Ltd). The specific capacitance of the electrode was obtained from $\mathrm{CV}$ curves according to the equation: ${ }^{34,35}$

$$
C_{\mathrm{s}}=\frac{4 \int I \mathrm{~d} U}{v \Delta U m}
$$

where the $C_{\mathrm{S}}\left(\mathrm{F} \mathrm{g}^{-1}\right)$ is the specific capacitance; $I(\mathrm{~A})$ is the current; $v\left(\mathrm{~V} \mathrm{~s}^{-1}\right)$ is the scan rate; $\Delta U(\mathrm{~V})$ is the applied voltage window and $m(\mathrm{~g})$ is the total mass of two electrodes.

The electrochemical impedance spectroscopy (EIS) (in $\left.58.5 \mathrm{~g} \mathrm{~L} \mathrm{~L}^{-1} \mathrm{NaCl}\right)$ was carried out using the $\mu$ AUTOLAB-III potentiostat (Metrohm, Switzerland) controlled by FRA software with a two-electrode cell system.

\subsection{Capacitor assembly and desalination test}

The obtained two pieces of $\mathrm{PCNF}_{\beta-\mathrm{CD}}$ web were cut into a $50 \mathrm{~mm}$ $\times 70 \mathrm{~mm}$ sheet, and assembled into a CDI cell. The mass of each $\mathrm{PCNF}_{\beta-\mathrm{CD}}$ sheet is around $70-80 \mathrm{mg}$. Before CDI test, $0.5 \mathrm{~g} \mathrm{~L}^{-1} \mathrm{NaCl}$ solution was circulated in the cell by a peristaltic pump overnight to arrive at physical adsorption equilibration. The desalination experiment of the capacitor was performed in a $0.5 \mathrm{~g} \mathrm{~L}^{-1} \mathrm{NaCl}$ aqueous solution $(50 \mathrm{~mL})$ by a battery test system (LANHE, CT2001A, Wuhan, China). All the desalination experiments were done at room temperature with a flow rate of

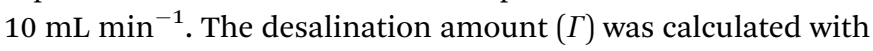
the following equation: ${ }^{34,36}$

$$
\Gamma=\frac{\left(c_{0}-c_{\mathrm{e}}\right) \times V}{m}
$$

where $\Gamma\left(\mathrm{mg} \mathrm{g}^{-1}\right)$ is the salt removal capacity, $c_{0}$ and $c_{\mathrm{e}}\left(\mathrm{mg} \mathrm{L}^{-1}\right)$ are the initial and final $\mathrm{NaCl}$ concentration in the solution, respectively; $V(\mathrm{~L})$ is the total solution volume. 


\section{Results and discussion}

\subsection{Characterization of fibers}

The surface morphology of the PAN/ $\beta$-CD NFs at different heat treatment stages was investigated in order to understand the structural variation of fibers. Fig. 1 exhibits the SEM images of the PAN/ $\beta$-CD NFs $(1: 0.8)$ in comparison with pure PAN-based pristine NFs $(1: 0)$ at different heat treatment stages. The pristine PAN/ $\beta$-CD NFs present a rough surface. After carbonization, the obtained $\mathrm{PCNF}_{\beta-\mathrm{CD}}$ exhibits a porous structure, and the pores are also found inside the fiber as shown in the crosssection image in the bottom-left inlay of Fig. 1F. In contrast, pure PAN-based pristine NFs $(1: 0)$ keep a smooth surface and no pores are found before and after heat treatment. The rough surface of fiber is probably caused by phase separation in the PAN/ $\beta$-CDs composite owing to various evaporation ratio of solvent and/or hydrophobic-hydrophilic interaction. ${ }^{37} \beta-\mathrm{CD}$ molecules are supposed to be bonded together tightly by
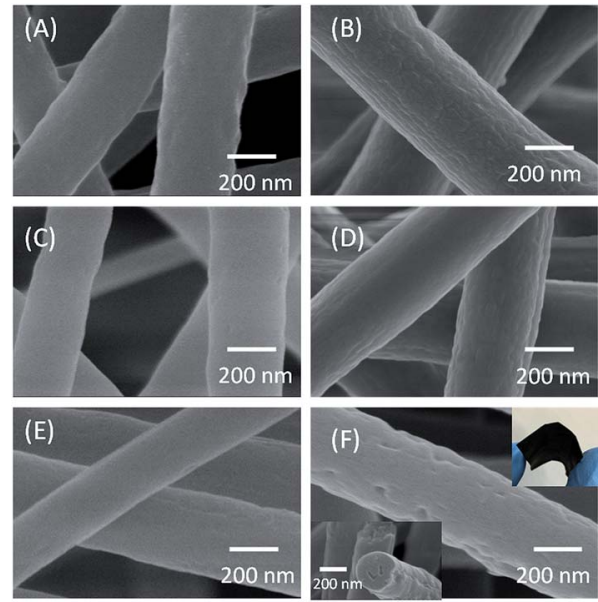

Fig. 1 SEM images of the electrospun pristine nanofibers (A, B), preoxidized nanofibers $(C, D)$, and $P C N F_{\beta-C D}(E, F)$ made from pure PAN $(A, C, E)$ and $P A N / \beta-C D(B, D, F)$. The cross section image is at the leftbottom of (F). Upper-right inlay of image $(F)$ is the photo image of the flexible $P C N F_{\beta-C D}$ sheet. hydrogen bonding interaction. Upon high temperature treatment, the cavity structure is broken with pores being formed in companying with the dehydration and decomposition of $\beta$-CD phase. Scheme 1 illustrates the pore-forming process of the $\mathrm{PCNF}_{\beta-\mathrm{CD}}$. In addition, the obtained porous fibers are still flexible (upper-right inlay of Fig. 1F) and easy to be handled as a self-supporting electrode for electrochemical experiment.

Fig. 2 exhibits the SEM images of $\mathrm{PCNF}_{\beta-\mathrm{CD}}$ obtained with different PAN/ $\beta$-CD blend ratios. Clearly, with the increase of $\beta-\mathrm{CD}$, the $\mathrm{PCNF}_{\beta-\mathrm{CD}}$ surface became rougher and presents more pores. This further confirms that $\beta$-CD plays a major role in forming the pores in the $\mathrm{PCNF}_{\beta-\mathrm{CD}}$. Whereas the pores disappear when the PAN/ $\beta$-CD ratio arrives at $1: 1$ (Fig. $2 D$ ), and some grooves are found, due to phase separation and shrinkage of fibers. Meanwhile, the fiber web becomes brittle, which makes CDI cell assembling difficult and causes poor conductivity in the further electrochemical study.

The TG analysis measurement was conducted in order to reveal the dehydration and decomposition of $\beta$-CD. Fig. 3 shows the TG curves of pristine PAN and PAN/ $\beta$-CD fibers. Inset is the TG curve of pure $\beta$-CD. There is a slight weight loss below $100{ }^{\circ} \mathrm{C}$ for the pristine NF $(1: 0)$ sample owing to the release of residual DMF from the fiber, whereas for PAN/ $\beta$-CD NFs, an obvious loss in weight is found at $60-100{ }^{\circ} \mathrm{C}$ due to the removal of the adsorbed $\mathrm{H}_{2} \mathrm{O}$ in $\beta$-CD. Following a plateau, there is a gradual weight loss stage starting at $220{ }^{\circ} \mathrm{C}$, indicating the
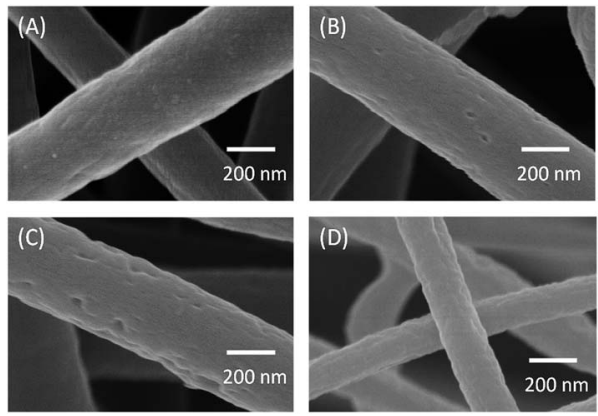

Fig. 2 SEM images of the $P C N F_{\beta-C D}$ produced with the PAN/ $\beta-C D$ ratio of (A) $1: 0.4$, (B) $1: 0.6$, (C) $1: 0.8$ and (D) $1: 1$.

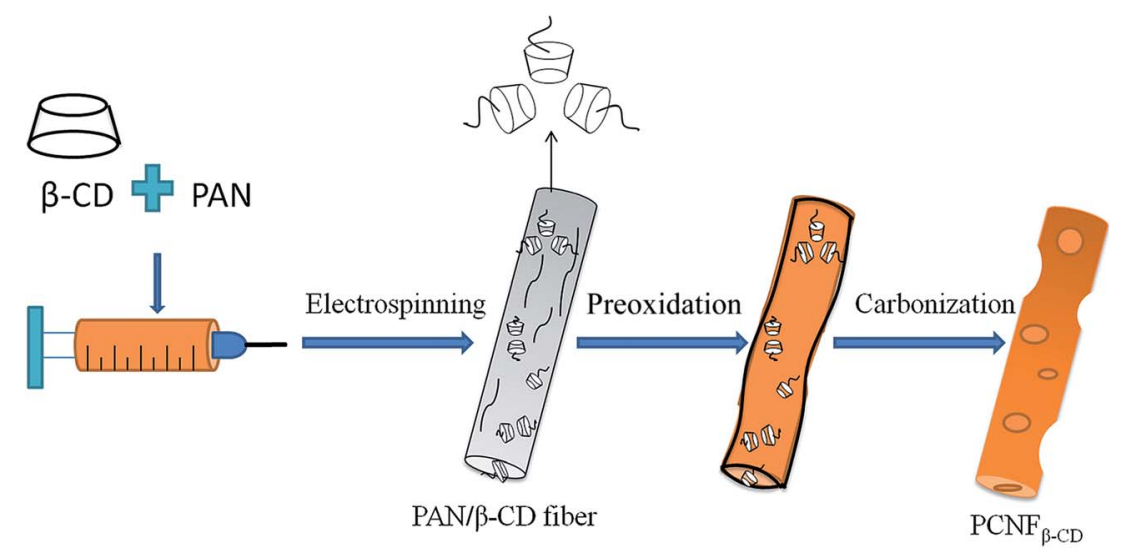

Scheme 1 The schematic illustration of the pore-forming progress on the $\mathrm{PCNF}_{\beta-\mathrm{CD}}$. 


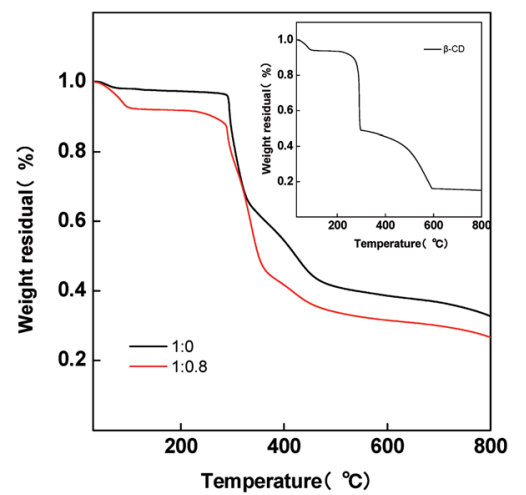

Fig. 3 Thermo-gravimetric curves of pristine PAN $/ \beta-C D$ nanofibers (1: 0 and $1: 0.8$ ). Inset is the TG curve of pure $\beta-C D$.

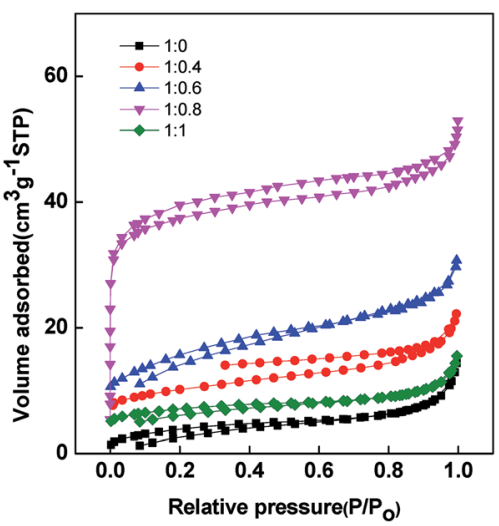

Fig. 4 Nitrogen sorption isotherms for $P C N F_{\beta-C D}$ obtained from different ratios of $P A N / \beta-C D$.

intramolecular or intermolecular dehydration of $\beta$-CD. As temperature further rises, $\beta$-CD phase continues to decompose. At the same time, the cyclization and carbonization of PAN phase occur when the temperature is over $300{ }^{\circ} \mathrm{C}$. The low carbon residual is obtained compared with pristine $\mathrm{NF}(1: 0)$. The production of large amount of $\mathrm{H}_{2} \mathrm{O}$ during decomposition of $\beta$-CD is supposed to be beneficial to the activation and the formation of micropores during carbonization. ${ }^{38}$

The pore structure of PAN $/ \beta$-CD with different blend ratios is examined by $\mathrm{N}_{2}$ adsorption/desorption isotherms, and the results are shown in Fig. 4 . Generally, the $\mathrm{N}_{2}$ uptake at a low relative pressure range of $0<p / p_{0}<0.1$ corresponds the relative volume of the micropores and the $\mathrm{N}_{2}$ uptake at pressure range of $0.5-0.6$ indicates the existence of mesopores. ${ }^{39,40}$ The adsorption volume of the pure PAN-based $\operatorname{PCNF}_{\beta-C D}(1: 0)$ is pretty low. It indicates that few pores exist in the fibers. With the addition of $\beta-\mathrm{CD}$, there is an obvious increase of adsorption in the low relative pressure zone. A steeper increase is found for the $\operatorname{PCNF}_{\beta-\mathrm{CD}}(1: 0.8)$ sample, suggesting the presence of micro pores. ${ }^{41}$ Moreover, it exhibits a type I plus IV adsorption accompanied with a type $\mathrm{H} 2 / \mathrm{H} 3$ hysteresis loop. This wide desorption hysteresis is usually due to the broad pore size distribution. ${ }^{42}$ The corresponding BET surface area and pore structure information of different $\mathrm{PCNF}_{\beta-\mathrm{CD}}$ are summarized in Table 1 . With the addition of the $\beta$-CD, the BET surface area and pore volume are improved obviously. In addition, the micropores are dominant in the fibers, which contributes to the specific surface area. ${ }^{43}$ However, $\operatorname{PCNF}_{\beta-\mathrm{CD}}(1: 1)$ obtained from high content of $\beta$-CD shows a poor performance due to severe shrinkage of the fibers and disappear of the pores, as observed in SEM image.

Raman spectroscopy is used to analyze the graphitization level of the carbon materials. As shown in the Raman spectra in Fig. 5, two peaks are found at $1358 \mathrm{~cm}^{-1}$ and $1580 \mathrm{~cm}^{-1}$, which correspond to the characteristic D and $\mathrm{G}$ peaks of carbon materials, respectively. ${ }^{38,44}$ The $\mathrm{D}$ band is ascribed to the amorphous carbon and defective graphitic structures in PCNF, whereas the $\mathrm{G}$ band is assigned to the $\mathrm{C}=\mathrm{C}$ stretching vibrations of graphite..$^{45}$ The ratio of $I_{\mathrm{D} / I_{\mathrm{G}}}$ is used to express the level of graphitization. ${ }^{46}$ The lower the $I_{\mathrm{D}} / I_{\mathrm{G}}$ ratio is, the higher crystallization and graphitization are achieved. With the increase of PAN/ $\beta$-CD ratios, G peak at the corresponding carbon fiber becomes clear and the $I_{\mathrm{D}} / I_{\mathrm{G}}$ ratio becomes low,

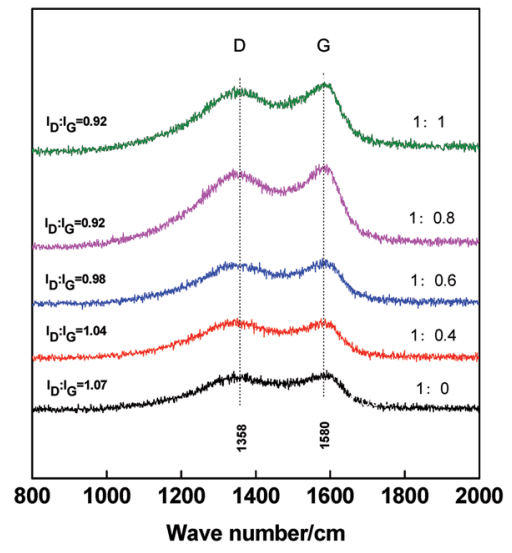

Fig. 5 Raman spectra of $\mathrm{PCNF}_{\beta-C D}(1: 0,1: 0.4,1: 0.6,1: 0.8$ and $1: 1)$.

Table 1 Pore characteristics of different $P C N F_{\beta-C D}$ materials

\begin{tabular}{lcllll}
\hline Samples & $S_{\text {BET }}\left(\mathrm{m}^{2} \mathrm{~g}^{-1}\right)$ & $V_{\text {total }}\left(\mathrm{cm}^{3} \mathrm{~g}^{-1}\right)$ & $V_{\text {meso }}\left(\mathrm{cm}^{3} \mathrm{~g}^{-1}\right)$ & $V_{\text {micro }}\left(\mathrm{cm}^{3} \mathrm{~g}^{-1}\right)$ & Average pore size $(\mathrm{nm})$ \\
\hline $\operatorname{PCNF}_{\beta-\text { CD }}(1: 0)$ & 12.2 & 0.020 & 0.018 & 0.003 & 6.17 \\
$\operatorname{PCNF}_{\beta \text {-CD }}(1: 0.4)$ & 58.4 & 0.037 & 0.023 & 0.013 & 5.61 \\
$\operatorname{PCNF}_{\beta-\text { CD }}(1: 0.6)$ & 92.7 & 0.043 & 0.029 & 0.014 & 4.62 \\
$\operatorname{PCNF}_{\beta \text {-CD }}(1: 0.8)$ & 156.2 & 0.084 & 0.025 & 0.059 & 2.18 \\
$\operatorname{PCNF}_{\beta-\text { CD }}(1: 1)$ & 20.0 & 0.027 & 0.015 & 0.013 & 6.33
\end{tabular}




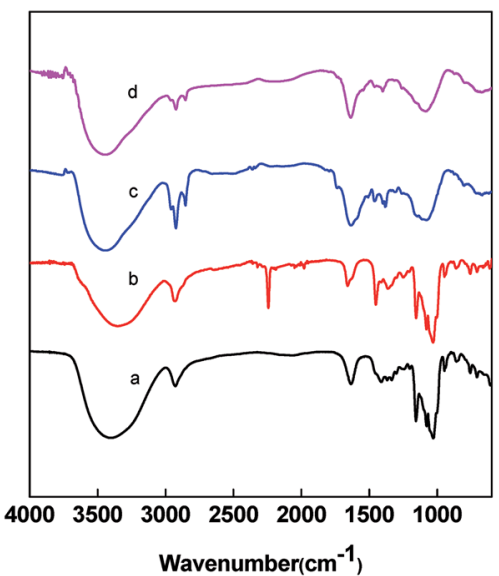

Fig. 6 FTIR spectra of $\beta-C D(a)$, pristine PAN/ $\beta-C D N F(b)$, preoxidized $N F(c)$ and $P C N F_{\beta-C D}(d)$.

indicating the improvement of graphitization. Therefore, the high graphitic carbon fibers are obtained with the addition of $\beta$ $\mathrm{CD}$, which is beneficial to the electrical conductivity of fibers.

FTIR spectra of the nanofibers at different heat treatment stages were scanned as shown in Fig. 6. The curve a of Fig. 6 exhibits the typical absorbance spectrum of pure $\beta-\mathrm{CD}$. The bands at 3382,2926 and $1150 \mathrm{~cm}^{-1}$ are assigned to the stretching vibration of $-\mathrm{OH}, \mathrm{CH} / \mathrm{CH}_{2}$ and the coupled $\mathrm{C}-\mathrm{C}-\mathrm{O}$ groups, respectively. ${ }^{47}$ In PAN $/ \beta-C D$, the characteristic vibration from $\beta-C D$ was found at 3421,2926 and $1160 \mathrm{~cm}^{-1}$. The band at $2250 \mathrm{~cm}^{-1}$ is assigned to the stretching vibration of nitrile group in PAN. It indicates the uniform doping of $\beta$-CD in the PAN fiber. After preoxidation and carbonization, the absorbance peaks of nitrile groups at $2280 \mathrm{~cm}^{-1}$ and C-C-O groups at $1020 \mathrm{~cm}^{-1}$ and $1150 \mathrm{~cm}^{-1}$ disappear, and the new bands at 2780 and $1100 \mathrm{~cm}^{-1}$ come out, indicating the decomposition of $\beta$-CD and occurrence of PAN cyclization.

\subsection{Electrochemical characterization}

CV measurements are widely applied as an effective way to determine the capacitance characteristics of electrode materials. Fig. 7A shows the cyclic voltammograms of the $\mathrm{PCNF}_{\beta \text {-CD }}$ electrode in a $58.5 \mathrm{~g} \mathrm{~L}^{-1} \mathrm{NaCl}$ aqueous solution. It presents the typical characteristics of the electric double layer capacitors. PCNF $\mathrm{P}_{\beta-\mathrm{CD}}(1: 0)$ shows a low specific capacitance. Based on eqn (1), the capacitance of the nanofiber $\mathrm{PCNF}_{\beta-\mathrm{CD}}$ $(1: 0)$ was calculated to be $9.5 \mathrm{~F} \mathrm{~g}^{-1}$. The low capacitance is due to the limited ion-adsorption sites and poor ionic diffusion at the nonporous carbon surface. With increasing the $\beta$-CD content, the $\mathrm{CV}$ curves become near to a rectangular shape, suggesting the rapid and efficient adsorption/desorption of ion at the electrode..$^{48}$ It proves that there are rich pores in $\mathrm{PCNF}_{\beta-}$ ${ }_{\mathrm{CD}}$, which facilitate the diffusion and transportation of ions. The higher the ratio of PAN/ $\beta$-CD is, the larger the specific capacitance is, and a $C_{\mathrm{s}}$ value of $174.4 \mathrm{~F} \mathrm{~g}^{-1}$ is obtained at the $\mathrm{PCNF}_{\beta}$ CD $(1: 0.8)$ electrode. However the capacitance current is pretty low on the $\operatorname{PCNF}_{\beta-C D}(1: 1)$ electrode, due to the severe shrinkage of fibers and disappearance of pores.

EIS is used to determine the conductivity of CDI electrode and ionic diffusion properties. ${ }^{49}$ Fig. $7 \mathrm{~B}$ shows the impedance plots of the $\mathrm{PCNF}_{\beta-\mathrm{CD}}$ electrodes. The intersection of the curves at the real axis at the high-frequency position represents the cell resistance. The semicircle diameter represents the charge transfer resistance $\left(R_{\mathrm{ct}}\right)$. The slope of line at the low-frequency range indicates the diffusion behavior of ions. ${ }^{50,51} \operatorname{PCNF}_{\beta \text {-CD }}$ (1:0) presents a huge $R_{\mathrm{ct}}$ and low slope, indicating a high resistance and poor ionic diffusion. In contrast, $R_{\mathrm{ct}}$ of the $\mathrm{PCNF}_{\beta-\mathrm{CD}}$ electrodes reduces greatly and the slope at low frequency becomes inclining towards the imaginary axis, indicative of the rapid diffusion/adsorption and improved capacitor behavior. The $\operatorname{PCNF}_{\beta-\mathrm{CD}}(1: 0.8)$ has the best conductivity and fastest ionic transportation, whereas $\mathrm{PCNF}_{\beta-\mathrm{CD}}$ (1:1) presents high resistance due to breaking of carbon sheet and poor contact to current collector.

\subsection{Capacitive deionization measurements}

$\mathrm{PCNF}_{\beta-\mathrm{CD}}$ sheets as a self-supporting electrode are assembled in parallel in the symmetric capacitor cell to evaluate the desalination performance of the electrodes. All the desalination experiments are performed in $0.5 \mathrm{~g} \mathrm{~L}^{-1} \mathrm{NaCl}$ solution. The
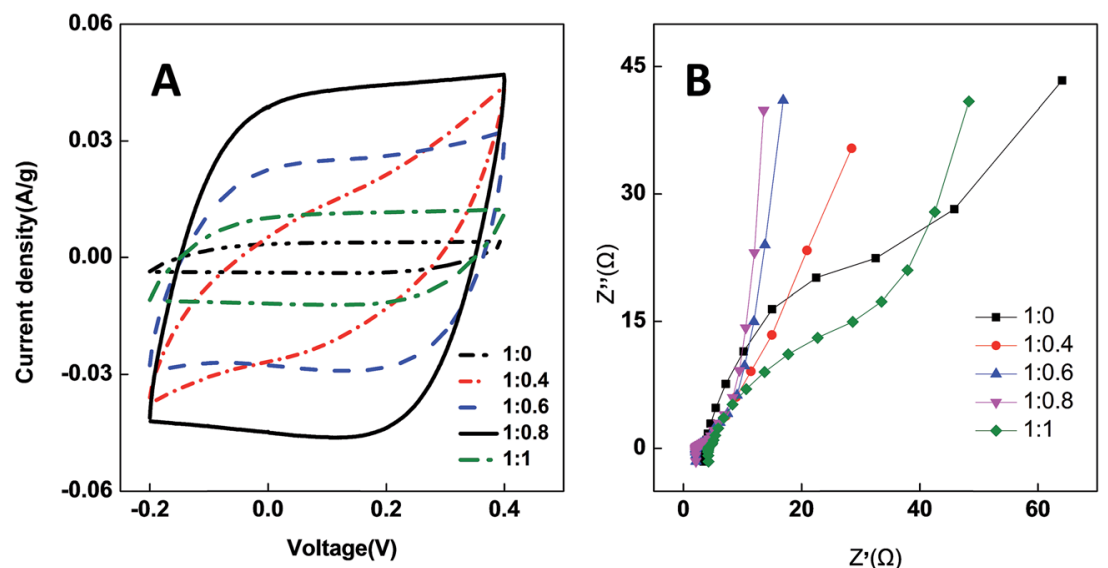

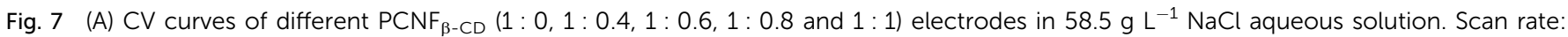
$1 \mathrm{mV} \mathrm{s}^{-1}$; (B) impedance plots of different $P C N F_{\beta-C D}$ electrodes. 

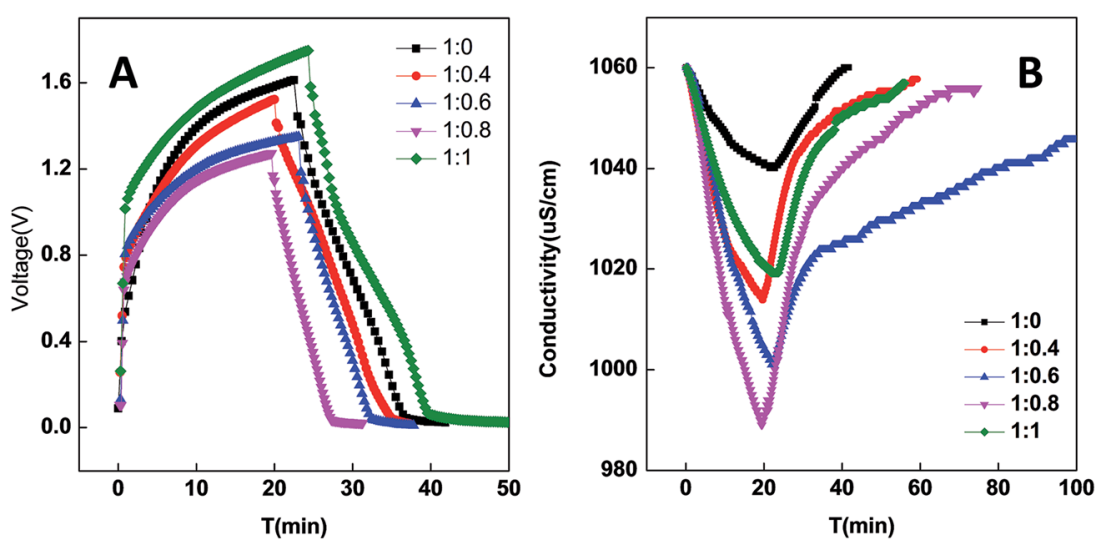

Fig. 8 Voltage variation during a charge-discharge process of capacitor (A), and conductivity variation (B) of CDI cell. Charging current: $80 \mathrm{~mA} \mathrm{~g}^{-1}$, charge quantity: $2 \mathrm{~mA} \mathrm{~h}$.

desalination is near to equilibration when a charge input of 2 $\mathrm{mA} \mathrm{h}$ was used in a CDI cell, and additional adsorption is ignorable when more charge ( $2.5 \mathrm{~mA} \mathrm{~h})$ was applied. Therefore, the constant current density during the charge process is applied and charging is terminated when the charge input of 2 $\mathrm{mA} \mathrm{h}$ is achieved in the cell. The electrode performance can be reflected from the cell voltage during the charging process. Fig. 8A and $\mathrm{B}$ exhibit the voltage variation and solution conductivity variation of the CDI cell containing different $\mathrm{PCNF}_{\beta-\mathrm{CD}}$ electrodes in one charging-discharging cycle, respectively. $\mathrm{PCNF}_{\beta-\mathrm{CD}}(1: 0)$, the control one, exhibits a fast voltage rising, indicative of low capacitance, and a pretty low variation of conductivity is obtained (Fig. 8B). In contrast, the $\operatorname{PCNF}_{\beta-C D}(1: 0.8)$ electrode exhibits excellent capacitance characteristics, with a low cell voltage (around $1.25 \mathrm{~V}$ ) at the end of charging step, and a fast conductivity descent is found in Fig. $8 \mathrm{~B}$, indicating a fast ion transportation and large salt adsorption capacity. $\operatorname{PCNF}_{\beta-\mathrm{CD}}(1: 1)$ shows a high IR drop upon a current being applied. This $\operatorname{PCNF}_{\beta-\mathrm{CD}}(1: 1)$ is fragile and hard to be assembled as a self-supporting electrode in the CDI cell. This may result in high resistance and unfavorable charge transportation along fibers. In light of the conductivity variation, the desalination amount $(T)$ is calculated using eqn (2) and the $\Gamma$ values of different electrodes are summarized in Table 2, together with the cell voltage. It concludes that the conductivity of the porous $\mathrm{PCNF}_{\beta-\mathrm{CD}}$ electrode is increased, and the ion adsorption is improved with the addition of appropriate amount of $\beta$-CD. The desalination amount of $11.65 \mathrm{mg} \mathrm{g}^{-1}$ is

Table 2 Capacitor and deionization performance of $P C N F_{\beta-C D}$ from different blend polymers

\begin{tabular}{lclll}
\hline Electrodes & \multicolumn{5}{c}{$\begin{array}{l}\text { Terminal } \\
\text { voltage (V) }\end{array}$} & IR drop (V) & $\Gamma\left(\mathrm{mg} \mathrm{g}^{-1}\right)$ \\
\hline $\operatorname{PCNF}_{\beta-\mathrm{CD}}(1: 0)$ & 9.5 & 1.6 & 0.16 & 2.80 \\
$\operatorname{PCNF}_{\beta-\mathrm{CD}}(1: 0.4)$ & 100.8 & 1.5 & 0.14 & 6.74 \\
$\operatorname{PCNF}_{\beta-\mathrm{CD}}(1: 0.6)$ & 141.6 & 1.3 & 0.11 & 8.34 \\
$\operatorname{PCNF}_{\beta-\mathrm{CD}}(1: 0.8)$ & 174.4 & 1.2 & 0.10 & 11.65 \\
$\operatorname{PCNF}_{\beta-\mathrm{CD}}(1: 1)$ & 53.4 & 1.7 & 0.17 & 3.28
\end{tabular}

achieved at the $\operatorname{PCNF}_{\beta-\mathrm{CD}}(1: 0.8)$ electrode, which is 5 times higher than that at the nonporous $\operatorname{PCNF}_{\beta-C D}(1: 0)$ electrode. The CDI performance of the current $\operatorname{PCNF}_{\beta-\mathrm{CD}}(1: 0.8)$ electrode is compared with those reported in the literatures and the results are summarized in Table 3 . The $\mathrm{PCNF}_{\beta-\mathrm{CD}}(1: 0.8)$ electrode presents an excellent desalination amount at the low voltage of $1.25 \mathrm{~V}$, compared to other porous carbons or hybrid carbon material.

The influence of current density on the desalination amount is investigated using a same charge input of $2 \mathrm{~mA} \mathrm{~h}$. As shown in Fig. 9, there is a slight increase in salt adsorption as current increasing, but descend at high current density. At the same time we found that the terminal cell voltage arrived at $1.5 \mathrm{~V}$ at the current density of $120 \mathrm{~mA} \mathrm{~g}^{-1}$. The polarization may happen at high current density, resulting in the decrease of the desalination amount since high voltage may cause water electrolysis $(>1.2 \mathrm{~V})$. The low cell voltage in CDI is favorable for a stable desalination which avoids the oxidation of electrodes. This present $\mathrm{PCNF}_{\beta-\mathrm{CD}}$ electrode can be operated in a wide current range of $60-100 \mathrm{~mA} \mathrm{~g}^{-1}$, in which a similar desalination amount

Table 3 Comparison of the desalination performance on different carbon nanofiber electrodes ${ }^{a}$

\begin{tabular}{lllll}
\hline $\begin{array}{l}\text { Carbon } \\
\text { material }\end{array}$ & $\begin{array}{l}\text { Initial NaCl conc. } \\
\left(\mathrm{mg} \mathrm{L}^{-1}\right)\end{array}$ & $\begin{array}{l}\text { Operating } \\
\text { voltage }(\mathrm{V})\end{array}$ & $\begin{array}{l}\text { Salt adsorption } \\
\left(\mathrm{mg} \mathrm{g}^{-1}\right)\end{array}$ & Ref. \\
\hline $\mathrm{PMMA} / \mathrm{PCNF}$ & 45 & 1.2 & 1.9 & 14 \\
$\mathrm{ACNF}$ & 500 & 1.2 & 10.5 & 52 \\
$\mathrm{DMSO}_{2} / \mathrm{PCNF}$ & 500 & 1.2 & 8.1 & 25 \\
$\mathrm{SG} / \mathrm{CNF}$ & 100 & 1.6 & 8.3 & 53 \\
$\mathrm{RGO} / \mathrm{ACNF}$ & 100 & 1.2 & 7.2 & 54 \\
$\mathrm{SnO}_{2} / \mathrm{CNF}$ & 50 & 1.2 & 3.42 & 55 \\
$\beta-\mathrm{CD} / \mathrm{PCNF}$ & 500 & 1.25 & 11.65 & This \\
& & & & work
\end{tabular}

${ }^{a}$ PMMA/CNF (porous carbon nanofibers derived with polymethyl methacrylate additive); ACNF (activated carbon nanofibers); $\mathrm{DMSO}_{2} /$ PCNF (porous carbon nanofibers with dimethyl sulfone as additive); SG-CNF (carbon nanofibers with sulfonated graphene additive); RGO/ ACNF (activated carbon nanofibers with reduced graphene oxide additive); $\mathrm{SnO}_{2} / \mathrm{CNF}$ (carbon nanofibers doped with $\mathrm{SnO}_{2}$ ). 


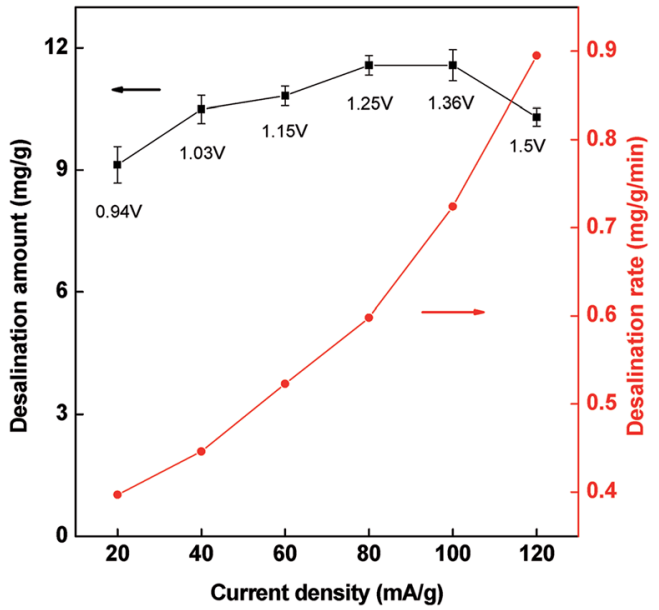

Fig. 9 Desalination amount and desalination rate versus the current density in the $C D I$ cell with $P C N F_{\beta-C D}(1: 0.8)$ as electrode. Charge input: $2 \mathrm{~mA}$ h.

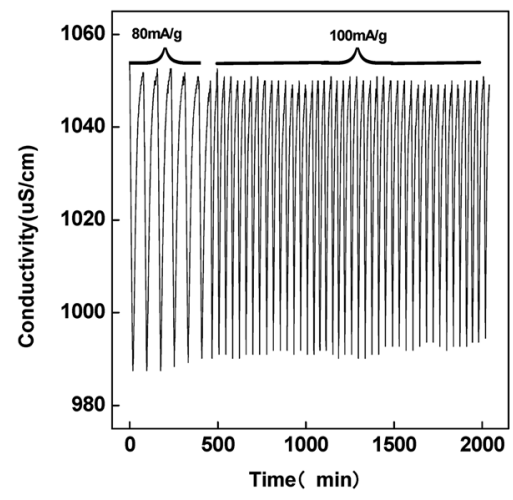

Fig. 10 Conductivity variation with time in the $\operatorname{PCNF}_{\beta-C D}(1: 0.8)$ capacitor cell during the continuous charge-discharge process by different current densities.

is obtained. Considering that the fast desalination rate is obtained at high current density (dotted curve), $100 \mathrm{~mA} \mathrm{~g}^{-1}$ of current density is preferred.

The cycle stability represents the regeneration performance of the CDI cell and the feasibility of practical application. The charging current was applied with the total charge amount of 2 $\mathrm{mA} \mathrm{h}$ in each cycle. Fig. 10 shows the conductivity variation of solution with time in near 50 charge-discharge cycles in $0.5 \mathrm{~g}$ $\mathrm{L}^{-1} \mathrm{NaCl}$ solution. At the charging current of $80 \mathrm{~mA} \mathrm{~g}^{-1}$, the charge process is slow, while it becomes fast and comparable desalination amount is achieved under $100 \mathrm{~mA} \mathrm{~g}^{-1}$ charging condition. There is only less than $85 \%$ decrease in desalination amount after 50 charge-discharge cycles. Therefore, the $\mathrm{PCNF}_{\beta}$ CD electrode is stable and renewable for CDI.

\section{Conclusion}

In summary, the self-supporting porous carbon fibers have been fabricated by electrospinning PAN/ $\beta$-CD followed by heat treatment. The meso/micro pores have been formed in the fibers due to the dehydration and decomposition of $\beta$-CD at high temperature. The obtained porous carbon fibers keep good flexibility with no break inside CDI cell. By adjusting the PAN/ $\beta$ $\mathrm{CD}$ ratio, the $\mathrm{PCNF}_{\beta-\mathrm{CD}}$ with high specific surface area and excellent electrochemical capacitor properties has been obtained. The optimal desalination amount of the electrode arrives at $11.65 \mathrm{mg} \mathrm{g}^{-1}$ with $\mathrm{PCNF}_{\beta-\mathrm{CD}}$ as CDI electrodes, which is 4 times as much as that of pure PAN-derived carbon fiber.

\section{Conflicts of interest}

There are no conflicts of interest to declare.

\section{Acknowledgements}

This work was financially supported by National Nature Science Foundation of China (Grant No. 21476047, 21105009, 21776045), Foundation of State Key of Electroanalytical Chemistry (Grant No. SKLEAC201205).

\section{References}

1 C. Huyskens, J. Helsen and A. B. de Haan, Desalination, 2013, 328, 8-16.

2 Y. A. C. Jande and W. S. Kim, Sep. Purif. Technol., 2013, 115, 224-230.

3 T. J. Welgemoed and C. F. Schutte, Desalination, 2005, 183, 327-340.

4 J.-H. Choi, Sep. Purif. Technol., 2010, 70, 362-366.

5 J.-S. Kim and J.-H. Choi, J. Membr. Sci., 2010, 355, 85-90.

6 Y.-J. Kim and J.-H. Choi, Water Res., 2012, 46, 6033-6039.

7 P. Xu, J. E. Drewes, D. Heil and G. Wang, Water Res., 2008, 42, 2605-2617.

8 M. C. Zafra, P. Lavela, G. Rasines, C. Macías, J. L. Tirado and C. O. Ania, Electrochim. Acta, 2014, 135, 208-216.

9 L. Zou, G. Morris and D. Qi, Desalination, 2008, 225, 329-340.

10 Z. Peng, D. Zhang, T. Yan, J. Zhang and L. Shi, Appl. Surf. Sci., 2013, 282, 965-973.

11 C. Tsouris, R. Mayes, J. Kiggans, K. Sharma, S. Yiacoumi, D. DePaoli and S. Dai, Environ. Sci. Technol., 2011, 45, 10243-10249.

12 X. Wen, D. Zhang, L. Shi, T. Yan, H. Wang and J. Zhang, J. Mater. Chem., 2012, 22, 23835.

13 A. G. El-Deen, N. A. M. Barakat, K. A. Khalil and H. Y. Kim, J. Mater. Chem. A, 2013, 1, 11001; New J. Chem., 2014, 38, 198-205.

14 A. G. El-Deen, N. A. M. Barakat, K. A. Khalil and H. Y. Kim, New J. Chem., 2014, 38, 198-205.

15 H. B. Li, Y. Gao, L. K. Pan, Y. P. Zhang, Y. W. Chen and Z. Sun, Water Res., 2008, 42, 4923-4928.

16 Y. Liu, H. B. Li, C. Y. Nie, L. K. Pan and Z. Sun, Desalin. Water Treat., 2013, 51, 3988-3994.

17 D. Zhang, T. Yan, L. Shi, Z. Peng, X. Wen and J. Zhang, J. Mater. Chem., 2012, 22, 14696-14704.

18 P. Liu, T. Yan, L. Shi, H. S. Park, X. Chen, Z. Zhao and D. Zhang, J. Mater. Chem. A, 2017, 5, 13907-13943. 
19 H. Wang, D. Zhang, T. Yan, X. Wen, J. Zhang, L. Shi and Q. Zhong, J. Mater. Chem. A, 2013, 1, 11778.

20 Z.-M. Huang, Y. Z. Zhang, M. Kotaki and S. Ramakrishna, Compos. Sci. Technol., 2003, 63, 2223-2253.

21 L. Zhang, A. Aboagye, A. Kelkar, C. Lai and H. Fong, J. Mater. Sci., 2013, 49, 463-480.

22 H. Niu, J. Zhang, Z. Xie, X. Wang and T. Lin, Carbon, 2011, 49, 2380-2388.

23 C. Tran and V. Kalra, J. Power Sources, 2013, 235, 289-296.

24 E. Jo, J.-G. Yeo, D. K. Kim, J. S. Oh and C. K. Hong, Polym. Int., 2014, 63, 1471-1477.

25 H. Pan, J. Yang, S. Wang, Z. Xiong, W. Cai and J. Liu, J. Mater. Chem. A, 2015, 3, 13827-13834.

26 H. Zhao, W. Han, W. Lan, J. Zhou, Z. Zhang, W. Fu and E. Xie, Electrochim. Acta, 2016, 222, 1931-1939.

27 X. Xie, X. Yin, L. Song, P. Du, N. Li, L. Qi and J. Xiong, Thin Solid Films, 2017, 636, 710-716.

28 H.-J. Oh, J.-H. Lee, H.-J. Ahn, Y. Jeong, Y.-J. Kim and C.-S. Chi, Thin Solid Films, 2006, 515, 220-225.

29 T. Loftsson, K. Matthiasson and M. Masson, Int. J. Pharm., 2003, 262, 101-107.

30 X. Wang, W. Xing, B. Wang, P. Wen, L. Song, Y. Hu and P. Zhang, Ind. Eng. Chem. Res., 2013, 52, 3287-3294.

31 Z.-C. Yang, Y. Zhang, J.-H. Kong, S. Y. Wong, X. Li and J. Wang, Chem. Mater., 2013, 25, 704-710.

32 A. Heydari, H. Khoshnood, H. Sheibani and F. Doostan, Polym. Adv. Technol., 2017, 28, 524-532.

33 M. Hayati-Ashtiani, Part. Part. Syst. Charact., 2011, 28, 71-76.

34 Y. Liu, T. Chen, T. Lu, Z. Sun, D. H. C. Chua and L. Pan, Electrochim. Acta, 2015, 158, 403-409.

35 M. D. Stoller and R. S. Ruoff, Energy Environ. Sci., 2010, 3, 1294.

36 T. Wu, G. Wang, Q. Dong, B. Qian, Y. Meng and J. Qiu, Electrochim. Acta, 2015, 176, 426-433.

37 D. Noreña-Caro and M. Álvarez-Láinez, Mater. Des., 2016, 95, 632-640.
38 J. Zhang, D. Xu, W. Qian, J. Zhu and F. Yan, Carbon, 2016, 105, 183-190.

39 X. Yu, J.-g. Wang, Z.-H. Huang, W. Shen and F. Kang, Electrochem. Commun., 2013, 36, 66-70.

40 X. Yu, C. Zhan, R. Lv, Y. Bai, Y. Lin, Z.-H. Huang, W. Shen, X. Qiu and F. Kang, Nano Energy, 2015, 15, 43-53.

41 X. Yu, J. Zhao, R. Lv, Q. Liang, C. Zhan, Y. Bai, Z.-H. Huang, W. Shen and F. Kang, J. Mater. Chem. A, 2015, 3, 1840018405.

42 H. Fan, F. Ran, X. Zhang, H. Song, W. Jing, K. Shen, L. Kong and L. Kang, J. Energy Chem., 2014, 23, 684-693.

43 G. Hasegawa, M. Aoki, K. Kanamori, K. Nakanishi, T. Hanada and K. Tadanaga, J. Mater. Chem., 2011, 21, 2060.

44 X. Liu, Y. Zhou, W. Zhou, L. Li, S. Huang and S. Chen, Nanoscale, 2015, 7, 6136-6142.

45 E. Samuel, H. S. Jo, B. Joshi, H. G. Park, Y. I. Kim, S. An, M. T. Swihart, J. M. Yun, K. H. Kim and S. S. Yoon, Appl. Surf. Sci., 2017, 423, 210-218.

46 H. Wang, L. Shi, T. Yan, J. Zhang, Q. Zhong and D. Zhang, J. Mater. Chem. A, 2014, 2, 4739-4750.

47 L. Ji and X. Zhang, Mater. Lett., 2008, 62, 2161-2164.

48 H. Li, S. Liang, J. Li and L. He, J. Mater. Chem. A, 2013, 1, 6335.

49 R. Kötz, M. Hahn and R. Gallay, J. Power Sources, 2006, 154, 550-555.

50 H. R. Ghenaatian, M. F. Mousavi, S. H. Kazemi and M. Shamsipur, Synth. Met., 2009, 159, 1717-1722.

51 A. K. Mishra and S. Ramaprabhu, J. Phys. Chem. C, 2011, 115, 14006-14013.

52 J. Liu, S. Wang, J. Yang, J. Liao, M. Lu, H. Pan and L. An, Desalination, 2014, 344, 446-453.

53 B. Qian, G. Wang, Z. Ling, Q. Dong, T. Wu, X. Zhang and J. Qiu, Adv. Mater. Interfaces, 2015, 2, 1500372.

54 Q. Dong, G. Wang, B. Qian, C. Hu, Y. Wang and J. Qiu, Electrochim. Acta, 2014, 137, 388-394.

55 A. S. Yasin, J. Jeong, I. M. A. Mohamed, C. H. Park and C. S. Kim, J. Alloys Compd., 2017, 729, 764-775. 